\title{
Intermodal Transportation Using Inland Water Transport in Russia and Abroad
}

\author{
Svetlana Miloslavskaya ${ }^{1 *}$, and Anna Myskina ${ }^{1}$ \\ ${ }^{1}$ Moscow State Academy of Water Transport, 2, Novodanilovskaya emb., Moscow, 117105, Russia
}

\begin{abstract}
Advantages of specific modes of transport can be best taken by employing various technologies of combined transport. In the up-to-date logistic schemes based on the "just-in-time" and "just-in-sequence" concepts, it is most appropriate to use railway service and inland water connection as the most environmentally friendly and effective modes designed and built for medium- and long-distance freight transportation. The development strategy of the Russian Federation's inland water transport for the period until 2030 is aimed at providing conditions under which to improve the sustainability of domestic transport system with due regard to shifting the balance between transport modes by switching some portion of cargo traffic from overland modes of transport to inland water transport.
\end{abstract}

\section{Introduction}

The transport strategy of the Russian Federation for the period until 2030 specifies toppriority goals in developing the transportation system in Russia [11]. This strategy provides for the traffic volume growth before 2030, as compared to 2007 , in the range of $30 \%$ to $50 \%$ in relation to domestic shipping operations as well as to export- and import-oriented traffic, both for a conservative road map and for an innovative one. European experts also predict the growth of freight traffic, as compared to 2005 , by a factor of 1.4 by 2030 , and by a factor of 1.8 by 2050 [15]. It is evident that this projected growth cannot be achieved due to the correspondingly extended transport infrastructure because of the limited funding needed for such a merely extensive scenario in developing the transport system. Apart from this, this way of development would lead to an increase in the negative effect of road transport upon the environment.

Furthermore, the freight transportation must be of minimal cost in the face of a considerable rise in requirements on environmental friendliness, energy efficiency, reliability and security of transport system. Under current conditions, a focus should be made on the level of intensity in using the infrastructure and transport means of different modes of transport -road, rail, sea and inland water transport. It is common knowledge that the overland modes of transport, especially road and rail, both in Russia and in many European countries, practically have no spare capacity. In contrast to these types of transport, the inland water transport has a lot of untapped potential [10-16]. A variety of combined transportation

*Corresponding author: miloslavskayasv@mail.ru 
technologies help to most fully take advantages of individual modes of transport integrated into door-to-door transportation chain.

\section{Material and methods}

The world processes of production-oriented globalization have resulted in a considerable increase in the length of the supply and distribution chains of the international trade. Insofar as railway and river transports are very efficient as bulk haulers, particularly over medium and long distances, these modes of transport are best suited for modern logistic supply systems based on the "just-in-time" and "just-in-sequence" concepts.

It is important to note that multimodal transportation, i.e. carriage of goods by two or more modes of transport, is considered to be the most environmentally friendly as long as the involvement of road transport in such a hauling is kept as small as possible and designed for collection and delivery at the route start or at the point of destination respectively. In so doing, the major part of the multimodal route is covered by inland waterways, marine transport or rail. Thus, it becomes possible to reduce a negative effect of transport upon the environment by modal shift of both freight and passengers traffic.

In the international practice, the combined transportation is referred to as multimodal transportation, the term implying "carriage of goods by two or more modes of transport" [6]. A separate segment of multimodal transportation is with intermodal transportation, i.e. "system of transport whereby two or more modes of transport are used to transport the same loading unit in an integrated manner, without loading or unloading, in door-to-door transport chain" [6]. With the intermodal transportation, the major part of the multimodal journey is by inland waterways, short sea shipping or rail, while road transport is, as a rule, used at the initial or/and final legs of the journey. Shipping operations as per the above flowchart are termed as combined. The international practice treats the notions of combined transportation and intermodal transportation as synonyms [3]. Consequently, the notions of multimodal transportation are of broader character as compared to intermodal transportation. With the multimodal transportation, one of the transport operators shall organize all the door-to-door service, for example, from a port of departure to a point of destination through one or more intermediate ports. If this transport operator assumes the whole responsibility for the performance, he shall issue a unified multimodal transport document (bill of lading, consignment note) confirming the presence of a contract on combined service, i.e. he takes on the role of a multimodal transport operator (MTO).

In the Russian Federation, the direct multimodal transport is an analogue of multimodal transportation, with this traffic being based on a unified transport document (a consignment) for all the cargo route. With such a transportation, the consignor is discharged from the involvement in transferring the cargo from one mode of transport to another and in producing respective documents. The direct multimodal transport provides for the interaction between railway service and other types of transport - water transport (sea transport, inland water transport), airline and road transport. In practice, however, the direct multimodal transport is in operation on the basis of legal regulations that contain "The Russian Federation Statute on Railway Transportation" [9] and "The Russian Federation Inland Water Transport Code" [8], i.e. direct multimodal railway-watertransport.

\section{Theory}

The direct multimodal railway-water transport culminated in its development in the middle 1970 s when the volume of transshipment from the railway transport to the water transport and vice versa reached $50 \mathrm{mln}$. tons on an annual basis, exceeding the 1940 level by a factor 
of 10. The share of transshipment operations under a unified transport document in the total river borne traffic increased, over the 30 years' period, from $7.2 \%$ to $10.5 \%$. In the transhipping cargo turnover, a prominent place was held by coal, mineral construction materials, ore, timber, breadstuffs and other bulk goods. According to statistics, the share of goods delivered by direct multimodal railway-water transport out of the total volume of river borne traffic have reached: $80 \%$ of stone coal, $79 \%$ of ore, $30 \%$ of salt and $25 \%$ of breadstuffs. About $70 \%$ of riverside ports were connected to the public railway network via access routes, with the majority of the ports being located in the European part of the country. The largest river ports have been built on the Volga and Kama rivers at freight traffic intersections of railroads originated from Siberia and the Urals. These transshipping ports' capacity made up $2.5 \mathrm{mln}$. tons, and they processed about a third of all the rest of cargo transshipment. A copious steady flux of combined traffic was associated with the transportation of coal from the Kuznetsk and Donets basins as well as from the Pechora and Karaganda basins to the addresses of numerous thermal power plants. Sizeable portions of iron-ore concentrate were transported in the specially designed oil-\&-ore carriers from the area of Kandalaksha (the Kola Peninsula) to the Cherepovets metallurgical complex, while petroleum products kept within special cargo bays of the same ships came in the reversed direction. Timber cargoes from the European North of the country were transported via direct multimodal railway-water transport for customers in forest-deficient areas in the south of the country.

For a variety of reasons, after the year of 1975 there observed a steady decline in the volume of transshipments through the direct multimodal railway-water transport system. Similar to this, there was a decrease in the share of goods delivered by direct multimodal railway-water transport out of the total volume of river borne traffic. Eventually, by 1990, i.e. prior to the downturn in the economy, rivers of the Russian Federation carried about 42 $\mathrm{mln}$. tons of cargoes under a unified (direct) transport document or about $7.5 \%$ of all the volume of public river borne traffic. Approximately $80 \mathrm{mln}$. tons of export- and importoriented cargoes were transported through railway-maritime traffic. Therefore, the total volume of direct multimodal railway-water traffic constituted over $120 \mathrm{mln}$. tons by the time when economic reforms in the country were ready to start. It should also be taken into account the volume of transported cargoes which were actually transferred from ship to train and vice versa, but under single modal transport documents for water part of the route and railway one. It is a case of cargoes which were transshipped at so called "clientele quays" (for example, the quays for grain elevators), i.e. the cargoes that related to the sphere of nonpublic transport. Thus, multimodal railway-water transport, put together, had a considerable proportion, and their total volumes were estimated to be about $200 \mathrm{mln}$. tons [3]. At present, "at the inland water ports of Russia, about $6 \mathrm{mln}$. tons of cargoes have been transshipped within the direct multimodal railway-water transport" [4].

In the Russian Federation, the technology of intermodal transportation involving water connection is at a near-zero level. The palletized-cargo and container transportation could be regarded as such a technology. According to the State statistics for 2015, the palletized-cargo and container transportation accounted for $0.8 \mathrm{mln}$. tons of cargoes, which constituted less than $1 \%$ of the total volume of cargoes transported by inland waterways [5]. The share of multi-tonnage containers with the gross weight of 10 tons and over in the total volume of general-purpose containers transported by the inland waterways amounted to $80 \%$. So, it can be said that container carriage via inland waterways has not yet gained a considerable amount. The main reason for this lies in the lack of purpose-designed container-carrying ships to deliver containers through estuary ports to the hinterland of the country. The underdeveloped infrastructure, in its turn, and the absence of up-to-date port facilities curb out the interests of ship-owners in constructing container-carrying ships. And as a consequence of this, at present only at 14 riverside ports located, as it happens, exclusively in the European part of the country there are facilities designed for handling 20-feet 
containers, and only at three of these ports - for 40-feet containers. As a result, this transportation is increasingly performed by roads and railways.

In Europe, intermodal transportation by inland waterways is more comprehensive and is basically a container service or ro-ro service between sea ports and hinterland regions. Marine containers delivered by sea are transshipped at sea ports to river ships under a sea-river scheme, and then through estuary river harbors they are delivered to customers in the continent part of the Europe. This makes it possible to save warehousing facilities and at the same time helps to relieve congestion on railroads and motorways. The containers are carried by specially designed river vessels which, depending on the infrastructure features of inland waterways, have the capacity of 32 to 500 TEU. For example, standard container-carrying ships on the Rhine are able to carry 200 containers. The ro-ro system via inland waterways is used to a lesser extent. A typical inland water vessel under the ro-ro scheme is able to carry about 70 trucks or road trains. Loading and discharging to and from such vessels are performed by horizontal method, i.e. by motor vehicles with their own wheels or wheels attached to it for that purpose.

In 2013, the three largest container ports of Europe, Rotterdam, Hamburg and Antwerpen, transshiped 11.6 millions, 9.3 millions and 8.6 millions of containers in TEU, respectively $[1,2]$. The ports of Rotterdam and Antwerpen handle from $90 \%$ to $100 \%$ of all the containers that are sent to North France, West and South Germany, Switzerland, and, through the port of Hamburg, to North and East Germany, Poland, Bavaria, and other places in European countries. Nearly a third of the total number of containers are transshipped from sea to river vessels to be delivered via inland navigation to hinterland regions of the above-mentioned countries $[7,8]$.

The most part of container carriage from the sea ports of Rotterdam and Antwerpen is transported down the Rhine where the containers are most often transshipped to trains or trucks to be delivered to the final destination. In 2013, according to this transportation scheme with the Rhine involved, there were transported over $2 \mathrm{mln}$. containers in TEU or $15.5 \mathrm{mln}$. tons of various cargoes. From year 2000 through 2013, the number of transported containers doubled due to an increase in the volume of traffic between the sea ports and inland regions. In contrast to the down-the-Rhine traffic, container carriage down the Rhine-Main-Danube canal is from year to year decreased as compared to the maximum value of 10 thousand containers in TEU in 2000. This is because of a great number of locks which slow down the delivery and make it costly as compared to the benchmark (in terms of cost and quality) of door-to-door delivery by road truck trailers $[7,16]$.

Nearly $25 \%$ of riverside ports on European inland waterways have terminals designed for intermodal transshipment. Annually, major river ports handle a significant number of marine containers, with a part of them coming or going aboard river vessels from/to sea ports. As is shown by an analysis of the volume and structure of containers transferred in the river ports to overland modes of transport in a series of European countries in 2014, the share of sea containers to be shifted to/from river vessels varies over a wide range from $15 \%$ to $40 \%$ at the ports of Duisburg, Rheinkargo (Neuss-Dusseldorf), Kehl, Stuttgart, Strasbourg, Paris, Lyon, Mulhouse) and from 50\% до $100 \%$ at the ports of Frankfurt, Mannheim, Koblenz, Braunschweig, Hannover, Worth, Emmerich, Weil, Ludwigshafen, Lille, Basel, Meerhout, Brussels, Liege. In terms of absolute values, the volumes of container transshipments to/from river vessels are much the biggest at the following river ports: Duisburg (455 thousand units), Rheinkargo (Neuss-Dusseldorf) (280 thousand units), Meerhout (225 thousand units), Paris (128 thousand units) [7].

In the EU member states, some EU-backed programmes have been implemented for the last two decades in order to cut back on toxic effects of transport upon the environment, to make away with traffic congestion to give a boost to security on the roads, and to promote the combined transport service $[5,16]$. It is obvious that such a short period is not sufficient 
to radically change the balance between different modes of transport, to create a sustainable alternative to road service, and to redirect the cargo traffic to more eco-friendly modes of transport or to combined transport service.

In the 1970s through 1980s, the government of the former USSR, with the aid of a whole bunch of economic measures, encouraged the domestic shipment by water transport and multimodal railway-water service. Under the conditions of planned socialist economy, some measures on tariff regulation were undertaken in order to shift traffic flows to inland waterways from railway routes which were parallel to these waterways. During the river navigation, premium charges were imposed for conveyance in bulk by train. Apart from this, clients received a discount of railway rates in the amount of $30 \%$ for the distance where cargoes were delivered to a port of transshipment and for the distance where cargoes were removed from this port. These and other measures favoured the rise of combined transports in the country at that time.

\section{Results}

The inland water transport development strategy for the period until 2030 approved in 2016 by the government of the Russian Federation puts the transport industry to similar tasks. This is a programmatic document treating the development of river transportation as "the key factor in lowering the overall environmental impact of the transport industry", with one of its objectives being with "the arrangement of conditions under which to reassign a portion of cargo traffic from the overland transport to the inland water transport" [10]. In a point of fact, the government regulation instruments to be used to impose restrictions on the carriage of mineral construction materials by road and to substantially abridge the traffic of overweight vehicles in cities located along inland waterways.

For the purpose of further enhancing the combined transport service involving inland water transport, the above Strategy sets the objective of creating nine trimodal (railway-roadriver) logistic centres to be a physical plant to involve the inland water transport in a transport logistical chain. To this end, a procedure of government support will be articulated for projects on developing such terminals through the use of the mechanism of public and private partnership.

\section{Conclusion}

A window of opportunities is going to open for intermodal transportation by inland waterways of Russia thanks to as-yet underutilized capacities of the Unified Deep Water System of European Russia which is an important waterway of international significance. The transport infrastructure of the Volga and Don rivers, including the Volga-Baltic Waterway, forms a constituent part of the International Transportation Corridor (ITC) "North-South", an international route with the total length of $7.200 \mathrm{~km}$ from St. Petersburg to the port of Mumbai (India). The ITC will make it possible to carry transit cargo flows, mainly containers, from Iran and Gulf countries through the territories of Azerbaijan and Russia and further to North and West Europe. The opening of appropriate sections of inland waterways within the Unified Deep Water System for foreign-flag ships will encourage the growth of Euroasian transportation along a shorter and more cost-effective route as compared to the now existing routes, in particular along the maritime route through the Suez Canal. Moreover, the combined rail and water service along the Northern Sea Route and down the Siberian Rivers opening onto the Trans-Siberian Railway may prove to be commercially viable when delivering goods from Western European countries. 
So, it can be said that a well-targeted and continuous work is needed in this area that, in the long run, will result in a quantum leap in the transport industry.

\section{References}

1. EU Transport in figures. Statistical pocketbook. 152 p. (2016)

2. S.V. Miloslavskaya, K.I. Pluznikov. Multimodal and intermodal transport. M.: Transport. 368 p. (2001)

3. Protocol on Combined Transport on Inland Waterways to the AGTC. United Nations. 25 p. (2008)

4. Regulation (EC) No 1692/2006 of the European Parliament and the Council of 24 October 2006 establishing the second 'Marco Polo' (2006)

5. Russian Statistical Yearbook. Rosstat, Moscow, 724 p. (2015)

6. Terminology on combined transport. Economic Comission for Europe (UN/ECE). New York and Geneva, 69 p. (2001)

7. The power of inland navigation. The future of freight transport and inland navigation in Europe. BVB, 68 p. (2017)

8. The Russian Federation Inland Water Transport Code of 07.03.2001 No. 24-FZ - M., (2001)

9. The Russian Federation Statute on Railway Transportation of 10.01.2003 No. 18-FZ

10. The Strategy for development of inland water transport of the Russian Federation for the period until 2030: [approved by the order of the Government of the Russian Federation: February 29, 2016 No. 327-r]. 37p. (2016)

11. Transport strategy of the Russian Federation for the period until 2030: [approved by the order of the Government of the Russian Federation: November 22, 2008 No. 1734r]. 70 p. (2008)

12. Transport for Sustainable Development. The case of Inland Transport. (UN/ECE), New York and Geneva, 255 p. (2015)

13. Transport and communications in Russia. Rosstat, Moscow, 2016. 112 p. (2016)

14. Transport 2050: The major challenges, the key measures. Memo, Brussels 11/197/2011. (2011)

15. Whitepaper «European transport policy for 2010: Time to decide», (COM (2001), Brussels, 118 p. (2011)

16. White paper on Efficient and Sustainable Inland Water Transport in Europe / UNECE. New York and Geneva. 76 p. (2011) 